\title{
The Evaluation of Synergy between University Entrepreneurship Education Ecosystem and University Students' Entrepreneurship Performance
}

\author{
Sheng-Yuan Wang $(\mathbb{D}$, Xiao-Lan Wu, Meng Xu, Quan-Xin Chen, and Ying-Jing Gu \\ Nanjing XiaoZhuang University, Nanjing, Jiangsu, China \\ Correspondence should be addressed to Sheng-Yuan Wang; 56439976@qq.com
}

Received 29 September 2021; Revised 20 November 2021; Accepted 5 December 2021; Published 18 December 2021

Academic Editor: Filippo Cacace

Copyright (c) 2021 Sheng-Yuan Wang et al. This is an open access article distributed under the Creative Commons Attribution License, which permits unrestricted use, distribution, and reproduction in any medium, provided the original work is properly cited.

\begin{abstract}
The interactive mechanism between college and university entrepreneurship education ecosystem and their students' entrepreneurial performance needs to be further discussed, as college and university students are an important force in entrepreneurship. Since there is a lack of symbiotic mechanism analysis and interactive optimization research using ecological methods, this paper constructs the evaluation index system of entrepreneurship education ecosystem and entrepreneurship performance evaluation index system and uses the entropy weight method to determine the weight of various indicators in the index system more objectively. In this paper, Lotka-Volterra model in ecology is used to deeply study the mechanism between college and university entrepreneurship education ecosystem and entrepreneurship performance. Lotka-Volterra multichoice goal programming (MCGP) model is used to optimize the collaborative relationship between college and university entrepreneurship education ecosystem and entrepreneurship performance. Finally, a numerical example is given to illustrate the feasibility and effectiveness of the research method. The results show that Lotka-Volterra multichoice goal programming (MCGP) method is effective in evaluating the synergy between college and university entrepreneurship education ecosystem and the students' entrepreneurship performance.
\end{abstract}

\section{Introduction}

Entrepreneurship is a systematic work for entrepreneurs to realize their own value, economic and social value. In this process, entrepreneurs create more value by optimizing and integrating available resources. Compared with other social groups, college and university students are potential owners of independent innovation spirit, with multidimensional characteristics such as professional knowledge, courage to explore, and relative age advantage. In the current economic and social transformation environment, college and university students use their knowledge and skills to establish various small and microenterprises and launch new products, services, and business models, which not only effectively alleviates the employment pressure of graduates, but also makes themselves an important force of national innovation. In order to promote the smooth development of students' entrepreneurial activities and more effectively support their entrepreneurship, more and more scholars have begun to study the influencing factors of college and university students' entrepreneurship.

Colleges and universities are not only an important place for knowledge dissemination and skill training, but also the cradle of entrepreneurial talent training. Through the research on the basic theory of entrepreneurship, colleges and universities spread the concept of social entrepreneurship, so as to promote the development of social entrepreneurship activities. At the same time, colleges and universities carry out social entrepreneurship education to cultivate students with entrepreneurial skills and reserve talents for social entrepreneurship. Colleges and universities have unique advantages in theoretical research, talent training, and skill 
training. Through cooperation with their students' enterprises, they can form an industry-university-research alliance to provide technical support and enterprise management services for students' enterprises. Colleges and universities are not only the fertile land for their students' entrepreneurs and entrepreneurial mentors, but also an important source of new technologies, new ideas, and new products. University education cultivates the important knowledge and skills of the students' entrepreneurs and makes it easier for them to find joint partners on the university campus. Entrepreneurship education on campus can teach student entrepreneurs to deal with the problems encountered during entrepreneurship and provide entrepreneurs with mentors' guidance, so that they can start a business better. Colleges and universities can also carry out industry-university-research cooperation to better develop new technologies and connect with market enterprises, so that the technology can be better commercialized. These greatly enhance the effectiveness of entrepreneurial technology. Colleges and universities have important support for talents of startup enterprises [1].

The research on the connotation and concept of entrepreneurship education has always been a research hotspot. Bechard and Toulouse [2], scholars of entrepreneurship education, believe that entrepreneurship education is a teaching model and process aimed at entrepreneurship or the development of small- and mediumsized enterprises. The representative definition also includes the recognition of entrepreneurship education by American scholars Colin and Jack [3]. They believe that entrepreneurship education is a learning opportunity, which provides individuals with the ability to recognize business opportunities. It is also an educational model to help individuals obtain theoretical knowledge, ability to observe, and other practical ability needed to carry out entrepreneurial activities. The existing literature shows that scholars generally believe that entrepreneurship education is of great value to the development of national and individual development. Kuratko et al. [4] believe that entrepreneurship education has made great contributions to the market economy. It not only changes the market structure, but also plays a key role in promoting innovation. From the perspective of students [5], entrepreneurship education helps to cultivate students' innovation ability and entrepreneurial skills and ensure that they have strong employability. Throughout the research on the connotation and concept of entrepreneurship education in recent years, although scholars have different expressions, the core content is basically the same, that is, to cultivate college and university students' good innovative spirit, entrepreneurial consciousness, and entrepreneurial ability. Researchers generally believe that entrepreneurship education, as a complex systematic project, is of positive significance to the construction of an innovative country, the cultivation of innovative talents in colleges and universities, and the allround development of the students.

After the 1980s, the scope of western educational ecology research has been broadened and deeply developed. Goodlad of the University of Washington pays more attention to the study of microschool ecology and first puts forward the concept of school as a "cultural ecosystem" [6]. Bowers is one of the educational ecologists with rich achievements in this period. His research includes not only microclassroom ecology but also macroeducational ecological problems such as education, culture, and ecological crisis [7]. On the basis of exploring the relationship between modern educational views and ecological crisis, David called for strengthening "ecological literacy" [8]. Scholars have different understanding of the research object of educational ecology, but they all emphasize the ecological thinking and ecological spirit of ecological synthesis, connection, and balance.

The introduction of ecological thinking into the research and practice of entrepreneurship education has become a new perspective of entrepreneurship education research in recent years, trying to borrow the research paradigm of ecology to find an effective way to improve the effectiveness of entrepreneurship education. Scholars have actively explored the connotation, characteristics, construction strategies and operation mechanism of entrepreneurship education ecosystem. Entrepreneurship education is a systematic project. Pittaway and Cope [9] propose to systematically understand entrepreneurship education. Cheng [10] believes that the significance of "ecosystem" for entrepreneurship education lies in the cooperative relationship between elements: each element in the system performs its own duties and interacts with the others and functions as a part of the whole. Keon [11] points out that colleges and universities are the core of the entrepreneurship education system. As the "convener," they promote the dialogue and communication among the key components of the system and produce a joint force in coordination with various elements of the community. As for the research on the connotation of entrepreneurship education ecosystem, the existing research mostly starts from "entrepreneurship ecology" and entrepreneurship education ecosystem is an important branch of entrepreneurship ecosystem.

In the research process of entrepreneurship education ecosystem, scholars generally first explore the elements of the system. Carvalho et al. [12] believe that the entrepreneurship education ecosystem should include three elements: entrepreneurship courses, extracurricular entrepreneurship projects, and auxiliary infrastructure. Dodd and Hynes [13] believe that the college entrepreneurship education ecosystem is gradually becoming regionalized, and the system construction process should clarify four aspects: entrepreneurship education goals, entrepreneurship education cost, differences between resources and opportunities, and the construction of entrepreneurship culture. Brush [14] believes that colleges and universities are in an important link in the regional entrepreneurship ecosystem, and the practice of entrepreneurship education within colleges and universities plays a key role. Entrepreneurship education in colleges and universities includes three interrelated key fields: entrepreneurship curriculum, entrepreneurship practice, and entrepreneurship research. Caiazza and Volpe [15] believe that the four pillars of the university entrepreneurship education ecosystem are all stakeholders, college and 
university entrepreneurship culture, infrastructure and network construction, scientific and technological achievements transformation office and entrepreneurship center.

As the main carrier of entrepreneurship education, curriculum is a bridge to transform ideas into educational practice, which directly affects the effect of entrepreneurship education. Therefore, entrepreneurship education curriculum has always been an important field of entrepreneurship education research. Brown [16] suggests that entrepreneurship education courses based on existing courses should also include creating business plans, entrepreneurial practice, business environment, politics, and education. Solomon et al. [17] believe that it is necessary to promote entrepreneurship courses in multiple disciplines, specifically involving entrepreneurship management, entrepreneurship law, and entrepreneurship financial accounting, so as to help students master the basic knowledge of entrepreneurship and legal operation.

The quality evaluation of entrepreneurship education is also the focus of academic research on entrepreneurship education. Robinson and Haynes [18] believe that assessing the quality of entrepreneurship education should be reflected in entrepreneurship courses. Lundstrm and Stevenson [19] have analyzed the public entrepreneurship policies of 15 countries and proposed that entrepreneurship policies can be evaluated from six aspects: entrepreneurship promotion, entrepreneurship education, entrepreneurship environment, entrepreneurship financing, business support in the initial stage, and target group strategy. Wilson et al. [20] have proposed that the evaluation content of entrepreneurship education mainly includes aspects: courses provided, social influence, and achievements of alumni.

At present, the research on entrepreneurship education ecosystem mainly focuses on the connotation of entrepreneurship education ecosystem, the evaluation methods of entrepreneurship education ecosystem, the theory of entrepreneurship education ecosystem, and the influencing factors of entrepreneurship education ecosystem. The existing scholars' definition of entrepreneurship education ecosystem is mainly combined with performance and entrepreneurship discipline research, and relevant theories and research measurement tools have been used to construct entrepreneurship education ecosystem, but the academic circles have not unified the connotation of entrepreneurship education ecosystem. Due to the different definitions of entrepreneurship education ecosystem and the understanding of entrepreneurship education objectives, as well as the multidimensional construction of entrepreneurship education, the measurement of entrepreneurship education ecosystem has not been unified.

Entrepreneurial performance is affected by many factors, which have been agreed upon by the academic community. The main factors are environment and opportunity factors, resource factors, strategic factors, entrepreneurs and their team factors, and some other factors. The existing research mainly analyzes and evaluates the output level and output performance of entrepreneurial activities from the existing theories and methods of enterprise performance evaluation.
This evaluation method ignores the particularity and heterogeneity of entrepreneurial enterprises, especially the lack of research on the entrepreneurial effect of college students' entrepreneurial groups. The future research on entrepreneurial performance will continue to expand to research objects such as entrepreneurial enterprises in different fields and different types of entrepreneurial subjects.

Based on the contributions of existing literature, this paper gives the following research hypotheses: (1) entrepreneurship education system has the characteristics of natural ecosystem. (2) There is a symbiotic and synergistic relationship between entrepreneurship education system and college students' entrepreneurship performance.

Generally, the literature on "ecology" in the research of entrepreneurship education in colleges and universities has increased in recent years. An analysis of entrepreneurship education by using ecology has a certain foresight for the disciplinary development of entrepreneurship in the future. However, according to the existing literature, the research on entrepreneurship education using ecology or educational ecology is still in the initial and exploratory stage, and the prominent problems mainly include the following aspects: (1) the concept of ecological research on entrepreneurship education needs to be further understood. At present, most studies focus on the elements, contents, and system construction of entrepreneurship education, but there are few studies on how to exchange, absorb, and coordinate the evolution of various elements through material flow, energy flow, and information flow. Most of the existing studies focus on the macrosystem; however, the key elements of the system lack ecological analysis from the microlevel, and without partial ecological analysis, the ecological generation of the overall structure will have inherent defects. There are few literatures on policy ecology, curriculum ecology, and classroom teaching ecology in entrepreneurship education. It is obviously not something that a discipline can undertake to improve the effectiveness of entrepreneurship education ecology. It needs to use the achievements of relevant disciplines as a reference or boost, such as the relevant achievements of ethics, pedagogy, ecology, and philosophy, so as to enrich and improve the theoretical basis of entrepreneurship education ecology and provide power for the ecological development of entrepreneurship education. (2) Most of the researchers have a certain preliminary understanding and research on ecology, but it is somewhat superficial in the research process of entrepreneurship education. Most of them are in the grafting stage of simple ecological terms. Although a large number of terms such as "entrepreneurship education ecology," "entrepreneurship education ecosystem," and "entrepreneurship education ecological concept" are used in the research, there is no clear definition of "entrepreneurship education ecology," which makes many achievements seemingly "ecological" but not really "ecological," even if they leave "ecology." The conclusion can also be deduced effectively or regardless of selfreliance, even if "ecology" is left out of the context; ecological thinking is not really integrated and embedded in the entrepreneurship education research. (3) The ecological research of entrepreneurship education needs to be broken 
through in the sense of methodology. At present, some scholars mostly borrow the basic terms or concepts in ecology and lack the overall structure of ecosystem in the way of ecological and systematic thinking. They should use the theories and methods of ecology to study the interaction and relationship between life subjects and their environment to study entrepreneurship education in colleges and universities. Entrepreneurship education in colleges and universities is a dynamic organism. We must use system thinking to observe the entire ecosystem in a global and allround way. (4) There is not enough research on the prerequisites for interdisciplinary research. Due to the differences in disciplines, the introduction of ecological thinking into entrepreneurship education is not a copy. There must be conditions, principles, and limitations for cross-disciplinary reference. The introduction of ecological analysis method into entrepreneurship education research will inevitably involve a limited condition, a basic principle, and an effective domain of reference or intervention, and there will be certain risks and warnings to some extent. At present, there is almost no research on risk aversion related to the ecological analysis of entrepreneurship education, which is likely to cause blindness and irregularities in subject reference. Researchers need to attach great importance to it. (5) The practical application of entrepreneurship education ecological research needs to be expanded. At present, few case studies are carried out on the construction and operation of entrepreneurship education ecosystem, and few studies are carried out on how to build a characteristic entrepreneurship education ecosystem for colleges and universities with different school running positioning types. Therefore, the direction of future research shall be strengthening the research on the operable mechanism of entrepreneurship education ecology, exploring the ecological path of entrepreneurship education development with the principles of "starting from our characteristics and facing the future in line with reality."

Therefore, in order to solve the above problems in relevant research, this paper determines the following research objectives: (1) A more reasonable and flexible university entrepreneurship education ecosystem rating index system and entrepreneurship performance evaluation index system is to be built. (2) Using the ecological model, this paper deeply studies the mechanism between the ecosystem of entrepreneurship education and entrepreneurship performance. (3) Using reasonable and effective ecological mathematics and planning model, this paper optimizes the collaborative relationship between entrepreneurship education ecosystem and entrepreneurship performance.

\section{Materials and Methods}

As shown in Figure 1, the research process of this paper is as follows.

Firstly, based on the existing research, this study constructs the university entrepreneurship education ecosystem and the evaluation index system of entrepreneurship performance. The entropy weight method is used to calculate the weight of the evaluation index and then evaluate the entrepreneurship education ecosystem and entrepreneurship performance of different evaluation units. Then, Lotka-Volterra MCGP model is used to optimize the interaction mechanism between entrepreneurship education ecosystem and entrepreneurship performance. A computational example is given to verify the effectiveness of the proposed method. According to the optimization results, the completion of the research objectives of this paper is analyzed.

\subsection{Evaluation of Entrepreneurship Education Ecosystem in} Colleges and Universities. The ecosystem of entrepreneurship education in colleges and universities is a complex system. The evaluation research of college and university entrepreneurship ecosystem is relatively rich. Based on relevant research [12-15], this paper constructs the following index system to evaluate the university entrepreneurship education ecosystem.

As shown in Table 1, the evaluation indicators of entrepreneurship education ecosystem in colleges and universities include entrepreneurship curriculum, entrepreneurship practice, entrepreneurship research, entrepreneurship culture, and entrepreneurship infrastructure. The evaluation of these indicators can be carried out by objective evaluation and subjective evaluation. The evaluation index system proposed in this paper has wide coverage, flexible evaluation methods, and better practicability.

\subsection{Measurement of Entrepreneurial Performance.} Improving entrepreneurial performance is an important task for entrepreneurs. How to scientifically measure entrepreneurial performance is the focus of entrepreneurial scholars. Due to the different understandings of the definition and objectives of entrepreneurship and the multidimensional construction of entrepreneurial performance, the academic measurement of entrepreneurial performance has not been unified, and the main measurement standards include financial indicators and nonfinancial indicators; subjective and objective indicators; long-term and shortterm indicators; profitability indicators and growth indicators.

For example, Robinson [21] uses financial indicators and objective indicators to measure entrepreneurial performance, including return on investment, changes in sales revenue, pretax interest income, net profit, return on sales, and return on assets. Abdel-Maksoud et al. [22] use nonfinancial indicators such as customer satisfaction, product quality, and timeliness of product supply to measure the entrepreneurial performance of manufacturing enterprises. Some scholars believe that objective entrepreneurial performance indicators are more appropriate than subjective indicators, as the objective indicators can overcome the influence of subjective factors. However, some scholars point out that it is not easy to accurately collect the objective financial performance of small- and medium-sized enterprises. The measurement standard of enterprise performance includes not only objective indicators, but also 


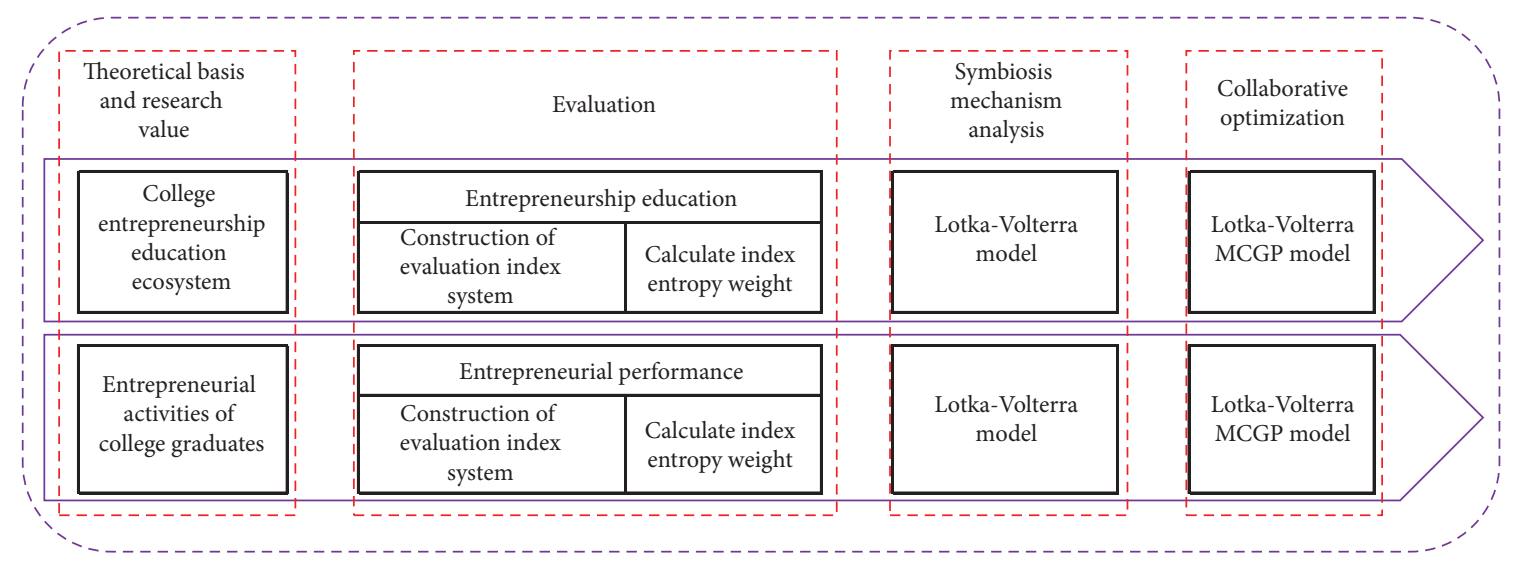

FIGURE 1: Research process.

TABle 1: Evaluation index of entrepreneurship education ecosystem.

\begin{tabular}{lcc}
\hline \multirow{2}{*}{ Indicators (code) } & \multicolumn{2}{c}{ Evaluation method } \\
& Objective evaluation (quantitative index) & Subjective evaluation (scoring) \\
\hline Entrepreneurship course (E1) & Number of entrepreneurship courses & Curriculum quality evaluation \\
Entrepreneurial practice (E2) & Entrepreneurial achievements & Evaluation of entrepreneurial activities \\
Entrepreneurship research (E3) & Research findings & Research evaluation \\
Entrepreneurial culture (E4) & Investment in cultural construction & Evaluation of entrepreneurial culture \\
Entrepreneurial infrastructure (E5) & Infrastructure investment & Entrepreneurship infrastructure evaluation \\
\hline
\end{tabular}

subjective indicators that cannot be reflected in the statements, such as customer satisfaction and loyalty [23].

The subjective measurement standard of entrepreneurial performance is gradually receiving attention from some scholars, but the main controversy of the subjective measurement indicator lies in the reliability and validity of the subjective data. Compared with the objective data, the results of the subjective data are more likely to be affected by the attitude, cognition, and data collection process of the evaluated person. In order to solve this problem, some scholars propose to further refine the dimension of indicators. Delaney and Huselid propose to divide the measurement of subjective performance into two aspects: cognitive organizational performance and cognitive market performance. Cognitive organizational performance includes employee relations, attracting and retaining talents, development of new products or services, customer satisfaction, etc., while cognitive market performance mainly includes profit rate, sales growth rate, and market share [24]. Other scholars have conducted comparative research on the effectiveness of subjective and objective measurement indicators of entrepreneurial performance. For example, Li found that the results obtained by using subjective and objective data are highly correlated through the analysis of subjective and objective data of financial indicators such as profit growth rate and sales growth [25].

These scholars mainly measure entrepreneurial performance from a static point of view, and some scholars reflect on the measurement of entrepreneurial performance from a dynamic point of view, and they believe that not only the profitability of the organization, but also the growth of the organization should be considered [26]. Antoncic and Hisrich divide profitability and growth into absolute and relative aspects and study enterprise performance from four perspectives [27]. Chrisman et al. put forward the concept of survival performance and divide entrepreneurial performance into two dimensions: survival and growth [28]. Cassia et al. have proposed that enterprise growth mainly refers to the growth rate of enterprise sales and market share [29].

Based on relevant research [21-29], this paper constructs the following index system to evaluate entrepreneurial performance.

As shown in Table 2, the evaluation indicators of entrepreneurial performance include financial indicators, customer satisfaction, organizational performance, market performance, and enterprise growth. The evaluation of these indicators can be carried out by objective evaluation and subjective evaluation. The evaluation index system proposed in this paper has wide coverage, flexible evaluation methods, and better practicability.

2.3. Data Processing Method and Flow. This paper evaluates the college and university entrepreneurship education ecosystem and entrepreneurial performance based on respondents scored. The evaluation matrix is $A$.

$$
A=\left[a_{i j}\right]_{m \times n} .
$$

Entropy method is used to determine the weight of the indicators in the evaluation index system. Entropy weight 
TABLE 2: Entrepreneurship performance evaluation index.

\begin{tabular}{lcc}
\hline Indicators (code) & \multicolumn{2}{c}{ Evaluation method } \\
& Objective evaluation (quantitative index) & Subjective evaluation (scoring) \\
\hline Financial index $(P 1)$ & Return on assets & Profitability evaluation \\
Customer satisfaction $(P 2)$ & Customer complaints & Customer satisfaction \\
Organizational performance $(P 3)$ & Turnover rate & Employee relationship evaluation \\
Market performance $(P 4)$ & Market share & Market evaluation \\
Enterprise growth $(P 5)$ & Sales growth rate & Enterprise growth evaluation \\
\hline
\end{tabular}

method increases objectivity [30]. Entropy was applied to deal with uncertainty [31]. The less the entropy value, the more the information that can be provided, and the bigger the weight that can be assigned to criterion [32]. The entropy weight is presented as follows [33]. Then initial evaluation matrix is

$$
\begin{aligned}
A & =\left[\begin{array}{cccc}
a_{11} & a_{12} & \cdots & a_{1 n} \\
a_{21} & a_{22} & \cdots & a_{2 n} \\
\vdots & \vdots & \ddots & \vdots \\
a_{m 1} & a_{m 2} & \cdots & a_{m n}
\end{array}\right] \\
& =\left[a_{i j}\right]_{m \times n}
\end{aligned}
$$

Step 1. Normalize the evaluation matrix:

$$
r_{i j}=\frac{a_{i j}}{\sqrt{\sum_{i=1}^{m} a_{i j}^{2}}} .
$$

Step 2. Calculate entropy:

$$
e_{j}=-\frac{1}{\ln m} \sum_{i=1}^{m} r_{i j} \ln r_{i j}, \quad j=1,2, \ldots, n .
$$

Step 3. Calculate the weights of each criterion:

$$
w_{j}=\frac{1-e_{j}}{\sum_{i=1}^{n}\left(1-e_{j}\right)}, \quad j=1,2, \ldots, n .
$$

Step 4. Construct weighted normalized evaluation matrix V:

$$
\begin{aligned}
v_{i j} & =w_{j} a_{i j}, \\
\sum_{j=1}^{n} w_{j} & =1 .
\end{aligned}
$$

Ecology has provided a complete and useful analysis method for today's humanities and social sciences research. After the "localization" of different disciplines, a unique research paradigm has been established in today's different disciplines, such as educational ecology, human ecology, social ecology, cultural ecology, management ecology, and so on. Of course, they jointly follow and continue the ecological worldview and methodology, including the values that embody ecology. Entrepreneurship education should think about and explore the problems related to theory and practice from the ecological perspective. The shift of ecological perspective establishes a thinking method for studying entrepreneurship education, which is actually a borrowing of ecological methods. It can be considered that entrepreneurship education research is a part of philosophy and social science research, and it is a general trend to use ecological perspective to study its related theoretical and practical problems, and it is a new attempt in research methods. At present, when constructing ecological civilization and emphasizing the coordinated development of man, nature, and society, it can be said that the perspective of ecological analysis is more far-reaching.

According to the logistic model [34-36], we constructed an internal dynamic system of population $1\left(P_{1}\right)$.

$$
\begin{aligned}
g_{1}(t) & =\frac{\mathrm{d} N_{1}(t)}{\mathrm{d} t} \\
& =\alpha_{1} N_{1}\left(1-\frac{N_{1}}{K_{1}}\right),
\end{aligned}
$$

$g_{1}(t)$ is the growth rate in phase $t . N_{1}(t)$ is population size of period $t$. $K_{1}$ is the maximum population scale. $\alpha_{1}$ is the intrinsic growth rate. $\left(1-\left(N_{1} / K_{1}\right)\right)$ is the retardation of growth.

The measurement model is as follows:

$$
\text { Because: } \begin{aligned}
\mathrm{d} N_{1}(t) & \approx \Delta N_{1}(t), \quad \Delta N_{1}(t)=N_{1}(t)-N_{1}(t-1), \\
\mathrm{d} t & \approx \Delta t=t-(t-1) \\
& =1 . \\
\text { So: } g_{1}(t) & \approx \Delta N(t) \\
& =\gamma_{1} N_{1}(t-1)+\gamma_{2} N_{1}^{2}(t-1) .
\end{aligned}
$$

Among them, $\gamma_{1}=\alpha_{1}$, and usually $\gamma_{1}>1$. It usually represents the synergy within a population. $\gamma_{2}=-\alpha_{1} / K_{1}$, and usually, $\gamma_{2}<0$. It refers to the competition effect within a population. It is called internal competition coefficient or population density inhibition coefficient. 
Similarly, the internal relation model of population 2 $\left(P_{2}\right)$ can be obtained:

$$
\begin{aligned}
g_{2}(t) & =\frac{\mathrm{d} N_{2}(t)}{\mathrm{d} t} \\
& =\alpha_{2} N_{2}\left(1-\frac{N_{2}}{K_{2}}\right) .
\end{aligned}
$$

The following system shows the impact of $P_{2}$ on $P_{1}$ :

$$
\begin{aligned}
g_{1}(t) & =\frac{\mathrm{d} N_{1}(t)}{\mathrm{d} t} \\
& =\alpha_{1} N_{1}\left(1-\frac{N_{1}}{K_{1}}+\frac{\beta_{12} N_{2}}{K_{2}}\right),
\end{aligned}
$$

where $\beta_{12}$ is the influence of population 2 on population 1 $\left(\beta_{12}>0\right.$, synergistic effect, $\beta_{12}<0$, competitive effect). Similarly, the follow system shows the impact of $P_{1}$ on $P_{2}$ :

$$
\begin{aligned}
g_{2}(t) & =\frac{\mathrm{d} N_{2}(t)}{\mathrm{d} t} \\
& =\alpha_{2} N_{2}\left(1-\frac{N_{2}}{K_{2}}+\frac{\beta_{21} N_{1}}{K_{1}}\right),
\end{aligned}
$$

where $\beta_{21}$ is the impact factor of population 1 on population 2. The dynamic system of $P_{1}$ and $P_{2}$ is

$$
\left\{\begin{array}{l}
g_{1}(t)=\frac{\mathrm{d} N_{1}(t)}{\mathrm{d} t} \\
=\alpha_{1} N_{1}\left(1-\frac{N_{1}}{K_{1}}+\frac{\beta_{12} N_{2}}{K_{2}}\right), \\
g_{2}(t)=\frac{\mathrm{d} N_{2}(t)}{\mathrm{d} t} \\
=\alpha_{2} N_{2}\left(1-\frac{N_{2}}{K_{2}}+\frac{\beta_{21} N_{1}}{K_{1}}\right) .
\end{array}\right.
$$

Equation (12) is called the Lotka-Volterra model. The Lotka-Volterra model simulates the dynamic relationship between the college entrepreneurship education ecosystem and entrepreneurial performance. Based on the numerical value of $\beta$, the type of interaction can be judged.

Among them, $1>\beta_{12}>0,1>\beta_{21}>0 . \beta_{12}$ is the contribution of system 2 to system 1 . According to the dependence and independence conditions, $1>\beta_{12}>0,1>\beta_{12}>0$. Multichoice goal programming (MCGP) is a useful method, and this paper builds Lotka-Volterra MCGP models for collaborative evaluation of entrepreneurship education ecosystem and entrepreneurship performance. In the basis of progress of related models [34-36], considering the symbiotic relationship, this problem can be formulated as follows:

$$
\left\{\begin{array}{l}
\text { Min } d_{1}^{+}+d_{1}^{-}+e_{1}^{+}+e_{1}^{-} \\
y=F\left(x_{1}, x_{2}\right), \quad x_{1}=E, x_{2}=P \\
y-e_{1}^{+}+e_{1}^{-}=O_{T} \\
x_{1}^{+}=\frac{k_{1}\left(1+\beta_{12}\right)}{1-\beta_{12} \cdot \beta_{21}} \\
d_{1}^{+}>=0 \\
e_{1}^{-}<0.001 \\
e_{1}^{+}=\frac{k_{2}\left(1+\beta_{21}\right)}{1-\beta_{12} \cdot \beta_{21}} \\
d_{1}^{-}<0.001 \\
0<\beta_{12}<1 \\
0<x_{21}<1
\end{array}\right.
$$

The Lotka-Volterra MCGP model is often used to analyze the symbiosis systems. Studies have shown that the Lotka-Volterra MCGP model can provide better analysis 
results. The main defect of this model is that the population dynamics model is mainly used to analyze the system operation mechanism with ecosystem attributes. The research objects in the study meet the requirements of ecosystem. The data of nonsymbiotic system is not suitable to be analyzed by this model. Relevant studies have verified the stability of this model, and different types of data do not affect the use of this model [34-36].

2.4. Example Analysis. In order to test the effectiveness of the analysis method proposed in this paper, an example is given in this section. The research object of this study is mainly college students with entrepreneurial activities or graduates with college degree. Traditional entrepreneurial survey is done usually directly through the contact email of entrepreneurial enterprises and teams to issue questionnaires, and a questionnaire survey is conducted. In order to effectively improve the quality and efficiency of questionnaire survey, this study adjusted the entrepreneurial questionnaire survey, mainly selecting the funded entrepreneurs in the university entrepreneurship Park, some participants in the 2020 National University Entrepreneurship competition, and the Internet plus. Some contestants in the college students' innovation and entrepreneurship competition are investigated. The distribution and recovery of questionnaire data are mainly carried out through email, paper delivery, and online filling. Meanwhile, during the questionnaire survey, the respondents were clearly informed that the survey was conducted anonymously to ensure that the survey content did not touch personal and corporate privacy, and it was promised that the survey results would only be used for academic research and would not disclose any relevant information.

The questionnaire survey was carried out from January 2021 to March 2021, and 221 questionnaires were collected. After that, the Invalid questionnaires with errors were deleted from this study. This research deleted the questionnaires repeatedly by the same respondents. The questionnaires with vacant answers, with perfunctory answers, and with inconsistent answers are all deleted. At last, this paper gets 176 valid questionnaires. The sampling process of this paper conforms to the norms of sampling statistics and the requirements of sample box, which can represent a wider population.

In this survey, 176 entrepreneurs with rich entrepreneurial experience graduated from 15 different universities and were interviewed with a questionnaire on the relationship between college and university entrepreneurial ecosystem and entrepreneurial performance. Based on the evaluation index system proposed above, the respondents used a 5-level scale to score. The scoring results are shown in the table below.

As shown in Table 3, the evaluation method based on entropy weight has been well used, and the distinction between the evaluation scores of entrepreneurship ecosystem in different universities is better.

As shown in Table 4, the evaluation method based on entropy weight has been well used, and the distinction between entrepreneurial performance evaluation scores of
TABLE 3: Evaluation of entrepreneurship education ecosystem.

\begin{tabular}{lcccccc}
\hline Unit & $E 1$ & $E 2$ & $E 3$ & $E 4$ & $E 5$ & Score \\
\hline U1 & 4.90 & 5.00 & 5.00 & 5.00 & 2.39 & 4.52 \\
U2 & 4.73 & 2.75 & 4.95 & 2.79 & 1.12 & 3.39 \\
U3 & 3.26 & 1.41 & 4.51 & 2.57 & 3.07 & 3.04 \\
U4 & 3.37 & 1.39 & 4.77 & 2.74 & 1.62 & 2.90 \\
U5 & 3.59 & 2.07 & 4.47 & 3.07 & 1.37 & 3.02 \\
U6 & 3.86 & 1.74 & 4.58 & 2.82 & 1.73 & 3.06 \\
U7 & 3.30 & 1.32 & 4.46 & 2.78 & 1.21 & 2.74 \\
U8 & 3.45 & 1.10 & 3.85 & 2.52 & 1.35 & 2.56 \\
U9 & 5.00 & 4.79 & 5.00 & 3.34 & 2.37 & 4.15 \\
U10 & 4.00 & 3.76 & 4.80 & 3.12 & 5.00 & 4.12 \\
U11 & 3.96 & 3.28 & 4.84 & 3.53 & 4.25 & 4.00 \\
U12 & 3.16 & 1.78 & 4.62 & 2.25 & 2.65 & 2.96 \\
U13 & 3.77 & 3.26 & 4.70 & 2.63 & 2.22 & 3.37 \\
U14 & 3.25 & 1.62 & 4.60 & 2.28 & 2.33 & 2.90 \\
U15 & 3.48 & 2.15 & 4.65 & 3.09 & 4.66 & 3.63 \\
Wj & 0.22 & 0.17 & 0.22 & 0.21 & 0.17 & \\
\hline
\end{tabular}

TABLE 4: Entrepreneurial performance evaluation.

\begin{tabular}{lcccccc}
\hline Unit & $P 1$ & $P 2$ & $P 3$ & $P 4$ & $P 5$ & Score \\
\hline U1 & 3.73 & 2.99 & 4.77 & 3.71 & 2.85 & 3.65 \\
U2 & 4.27 & 4.11 & 4.78 & 3.84 & 1.71 & 3.83 \\
U3 & 4.01 & 3.06 & 4.73 & 3.98 & 1.91 & 3.62 \\
U4 & 5.00 & 5.00 & 5.00 & 3.77 & 5.00 & 4.74 \\
U5 & 3.58 & 2.28 & 4.38 & 3.77 & 1.50 & 3.18 \\
U6 & 4.15 & 3.00 & 4.16 & 3.93 & 1.04 & 3.36 \\
U7 & 4.68 & 4.03 & 4.87 & 3.94 & 1.20 & 3.85 \\
U8 & 3.77 & 2.96 & 4.68 & 3.94 & 2.43 & 3.61 \\
U9 & 3.43 & 2.47 & 4.50 & 4.05 & 1.49 & 3.28 \\
U10 & 3.43 & 2.55 & 4.53 & 3.83 & 1.70 & 3.28 \\
U11 & 2.21 & 2.60 & 4.79 & 3.27 & 1.03 & 2.87 \\
U12 & 4.16 & 3.54 & 4.81 & 5.00 & 1.33 & 3.88 \\
U13 & 3.40 & 1.75 & 4.58 & 3.70 & 1.87 & 3.13 \\
U14 & 3.89 & 2.60 & 4.68 & 4.27 & 1.31 & 3.45 \\
U15 & 4.19 & 2.88 & 4.83 & 4.37 & 1.27 & 3.62 \\
Wj & 0.21 & 0.20 & 0.21 & 0.21 & 0.17 & \\
\hline
\end{tabular}

different evaluation units is better. The evaluation results provide a research basis for further analysis.

As shown in Table 5, description of optimization results shows that the larger the value of $\beta$, the more the room for improvement. U8 is the evaluation unit with the worst collaborative development level of entrepreneurship education ecology and entrepreneurship performance. The symbiotic system can reach the ideal state only when a relatively high synergy coefficient is obtained. The standard deviation of $\beta$ is used to explain the symmetry of the symbiotic system. If the cooperative behavior is single, it is defined as parasitic mode, which is not conducive to the long-term development of symbiotic system. The larger the standard deviation of the value of $\beta$, the greater the difference of the cooperation coefficient, and the worse the cooperation symmetry. In this example, the cooperative symmetry of U4 unit is the worst.

2.5. Policy Suggestion. At present, the development level of entrepreneurship education ecosystem in colleges and universities is uneven. Ignoring the ecological characteristics 
TABle 5: Solution of Lotka-Volterra MCGP model.

\begin{tabular}{lcccccc}
\hline Unit & $E$ & $P$ & $\beta_{12}$ & $\beta_{21}$ & Mean of $\beta$ & Std. deviation of $\beta$ \\
\hline U1 & 5.00 & 5.00 & 0.08 & 0.33 & 0.21 & 0.18 \\
U2 & 5.00 & 5.00 & 0.36 & 0.21 & 0.29 & 0.11 \\
U3 & 5.00 & 5.00 & 0.47 & 0.23 & 0.35 & 0.17 \\
U4 & 5.00 & 5.00 & 0.69 & 0.03 & 0.36 & 0.47 \\
U5 & 5.00 & 5.00 & 0.42 & 0.35 & 0.39 & 0.05 \\
U6 & 5.00 & 5.00 & 0.43 & 0.30 & 0.37 & 0.09 \\
U7 & 5.00 & 5.00 & 0.64 & 0.16 & 0.40 & 0.34 \\
U8 & 5.00 & 5.00 & 0.69 & 0.20 & 0.45 & 0.35 \\
U9 & 5.00 & 5.00 & 0.13 & 0.44 & 0.29 & 0.22 \\
U10 & 5.00 & 5.00 & 0.14 & 0.43 & 0.29 & 0.21 \\
U11 & 5.00 & 5.00 & 0.14 & 0.59 & 0.37 & 0.32 \\
U12 & 5.00 & 5.00 & 0.53 & 0.17 & 0.35 & 0.25 \\
U13 & 5.00 & 5.00 & 0.30 & 0.40 & 0.35 & 0.07 \\
U14 & 5.00 & 5.00 & 0.50 & 0.26 & 0.38 & 0.17 \\
U15 & 5.00 & 5.00 & 0.27 & 0.28 & 0.28 & 0.01 \\
Mean & 5.00 & 5.00 & 0.39 & 0.29 & 0.34 & 0.20 \\
\hline
\end{tabular}

of higher education will lead to the emergence and implementation of some policies, which not only has a negative impact on the development of higher education, but also destroys the ecological environment of higher education system. In recent years, with the deepening and popularization of the concept of sustainable development, its spiritual essence has penetrated into all levels of social development and plays a positive role in promoting the allround and healthy development of social economy. Similarly, the theory of sustainable development has also been introduced into the field of higher education research and has caused profound changes in the philosophy of higher education. To adhere to the concept of sustainable development, we can start from the following two aspects: (1) The social function of higher education should be strengthened. The social function of higher education is mainly realized through the talents trained by higher education. Therefore, cultivating a large number of high-quality talents is the prerequisite for the realization of the social function of higher education. In the development process of higher education, on the one hand, we should broaden professional fields, enhance the ability of knowledge innovation, and provide high-tech scientific and technological achievements and intellectual support for social and economic development. On the other hand, we should not ignore education of the students' political quality and humanistic quality and strive to cultivate students into compound talents with high political level and strong professional skills. (2) The selfconstruction of higher education should be strengthened. Higher education exists as a relatively independent ecosystem, and it is characteristic of naturalness and sociality. Naturalness is the operation law of education and teaching as training people in higher education. Sociality is the characteristic of personal socialization of higher education objects and socialization of higher education itself. As a subsystem of the society, higher education should not only meet the needs of society, but also constantly strengthen its own construction. Only by strengthening its own construction can it give better play to its own functions and better serve the society. Therefore, in the process of strengthening the self-construction of higher education, we should change the traditional concept of educational development, establish the concept of sustainable development, and enhance the ability and vitality of universities to run schools in accordance with the law.

\section{Results and Discussion}

This paper uses Lotka-Volterra model to make an in-depth study of the mechanism between college and university entrepreneurship education ecosystem and entrepreneurship performance. Using the MCGP model embedded in Lotka-Volterra equilibrium relationship, this paper analyzes the collaborative relationship between college and university entrepreneurship education ecosystem and entrepreneurship performance. Finally, a numerical example is given to illustrate the feasibility and effectiveness of the research method in this paper. The results show that Lotka-Volterra model can well describe the symbiotic relationship between college and university entrepreneurship education ecosystem and entrepreneurship performance. Entrepreneurship education and entrepreneurship activities in colleges and universities can be seen as symbiosis in an ecosystem, and the synergy between them can improve the system level of both. Lotka-Volterra MCGP method is used to evaluate the synergy between college and university entrepreneurship education ecosystem and university students' entrepreneurship performance.

Compared with the existing university entrepreneurship education ecosystem evaluation [12-15] and entrepreneurship performance research [21-29], the research indicators in this paper are more comprehensive and the index weight is more objective. The existing research on entrepreneurship education mainly focuses on the internal elements of entrepreneurship education. Compared with the existing research on entrepreneurship education [16-20], this paper conducts research from the perspective of the interaction mechanism between the performance of entrepreneurship activities and entrepreneurship education. This paper expands the theoretical basis, research perspective, mathematical methods, and optimal planning model of entrepreneurship education research.

The research findings of this paper have notable theoretical and practical significance. The theoretical significance of this paper is as follows: (1) focusing on the core issue of the covariant relationship between entrepreneurship education ecosystem and college students' entrepreneurship performance, this paper combines ecosystem theory with college students' entrepreneurship education and entrepreneurship practice and studies the impact of entrepreneurship education ecosystem on college students' entrepreneurship performance in combination with various laws and characteristics of ecosystem development. It can provide new research ideas for understanding the relationship between various stakeholders and the system operation mechanism in college students' entrepreneurship. (2) The introduction of population dynamics in ecological theory as a measurement method is helpful to provide an accurate explanation of the evolution mechanism of the system from 
quantitative change to qualitative change. (3) From the perspective of symbiosis and synergy, this paper studies the impact mechanism of entrepreneurship education ecosystem on college students' entrepreneurial performance. The research results can support and improve the theoretical system of entrepreneurship education ecosystem academically.

The practical significance of this paper is as follows: in the past, the design of entrepreneurship support policy mechanism is mostly from the leading perspective of policy makers and is less based on the analysis of the combination of system operation and subject behavior. It is difficult for the policies formulated to meet the needs of college students' entrepreneurship subjects. Based on the effective analysis of the system characteristics, evolution mechanism, and element synergy, this paper closely adheres to the subject status of college students, evaluates the survival suitability of college students' entrepreneurial population in the entrepreneurial ecosystem, and then designs a reasonable operation mechanism, takes supporting the entrepreneurial activities of college students' entrepreneurs as the core, and designs the operation mechanism and implementation policies of relevant entrepreneurial ecosystems, so as to overcome the shortcomings of previous studies; on the one hand, it can provide ideas for improving college students' entrepreneurial performance; on the other hand, it can enhance the feasibility and effectiveness of college students' entrepreneurial support policies and provide reference for relevant departments to formulate entrepreneurial support policies.

\section{Conclusion}

This paper completes the relevant research objectives and expands the research method of the symbiotic relationship between college entrepreneurship education ecosystem and entrepreneurship performance. The research highlights of this paper are as follows: (1) The rating index system and entrepreneurial performance evaluation index system of college and university entrepreneurship education ecosystem are built, and the entropy weight method is used to more objectively determine the weight of various indicators in the index system. (2) The Lotka-Volterra model in ecology is used to study in depth the mechanism between college and university entrepreneurship education ecosystem and entrepreneurship performance. (3) Lotka-Volterra MCGP model is used to optimize the collaborative relationship between college and university entrepreneurship education ecosystem and entrepreneurship performance.

Although this study has made useful progress, there are still deficiencies in this study, which need to be further improved in the future. The deficiencies of the research are as follows: (1) the scope of the investigation needs to be expanded. This paper studies the mechanism of the impact of entrepreneurial ecosystem on college students' entrepreneurship. The survey is mainly conducted by the funded entrepreneurs, the part of the "Youth" national university entrepreneurship competition, and China Internet plus students. The samples are mainly from Jiangsu Province,
Zhejiang Province, Shanghai City, and other regions. The limitations of the research samples may affect the universality of the research conclusions. Future research can expand the collection space of college students' entrepreneurial population samples and analyze the research problems in a wider range. (2) There is the dynamic adjustment of the evaluation index system of the impact of entrepreneurship education ecosystem on college students' entrepreneurship performance. This study constructs the impact index system of entrepreneurship education ecosystem on college students' entrepreneurship performance. At present, college students' entrepreneurial activities and entrepreneurial education ecosystem will change with the development of economic and social situation. Future research will focus on how to dynamically adjust the survival suitability evaluation index system of entrepreneurial population in the entrepreneurship education ecosystem according to environmental changes. (3) There are game and evolution of entrepreneurship education ecosystem. The entrepreneurship education ecosystem includes entrepreneurs, governments, universities, intermediaries, financial institutions, and other elements. The elements are interrelated and serve entrepreneurial activities. Similarly, there is a game between the elements. The game theory method is used to analyze its coordination and mechanism, promote the good operation of the entrepreneurship ecosystem, and analyze the evolution of the entrepreneurship ecosystem; it is one of the directions of future research.

In the future research, we need to consider the dynamic adjustment of the impact evaluation index system of college and university entrepreneurship education ecosystem on the students' entrepreneurship performance. In the information age, university students' entrepreneurship and the entrepreneurship education ecosystem will change with the development of the situation. The college and university entrepreneurship education ecosystem and entrepreneurship performance evaluation index system are not invariable but constantly adjusted and improved with the change of the environment. Future research will focus on how to dynamically adjust the entrepreneurship education ecosystem and entrepreneurship performance evaluation index system according to environmental changes.

\section{Data Availability}

The data used to support the findings for the study are included in the paper.

\section{Conflicts of Interest}

The authors declare that they have no conflicts of interest.

\section{Acknowledgments}

This work was supported by the Philosophy and Social Science Research Project for Universities of Jiangsu (Research on the co-evolution of innovation ecosystem in the era of digital economy in Jiangsu Province, Project no. 2021SJA0485). 


\section{References}

[1] C. Mason and R. Brown, "Entrepreneurial ecosystems and growth-oriented entrepreneurship," Final Report to OECD, Organisation for Economic Cooperation \& Development, Hague, Netherlands, 2014.

[2] J.-P. Bechard and J.-M. Toulouse, "Validation of a didactic model for the analysis of training objectives in entrepreneurship," Journal of Business Venturing, vol. 13, no. 4, pp. 317-332, 1998.

[3] J. Colin and E. A. Jack, "Contemporary approach to entrepreneurship education," Education \& Training, vol. 46, no. 8, pp. 416-423, 2004.

[4] D. F. Kuratko and D. F. Jennings, "Guest Editorial: Entrepreneurship and the Acquisition of Dynamic Organizational Capabilities," Entrepreneurship Theory and Practice, vol. 23, 1999.

[5] R. Lambert, "The Lambert Review of Business-University Collaboration," 2003, http://www.hm-treasury.gov.uk/d/ lambert_review_final_450.pdf.

[6] J. I. Goodlad, The Ecology of School Renewal: Eighty-Sixth Yearbook of the National Society for the Study of Education, National Society for the Study of Education, Chicago, IL, USA, 1987.

[7] C. A. Bowers and D. J. Flinders, Responsive Teaching: An Ecological Approach to Classroom Patterns of Language," Culture and Thought, Teachers College Press, NewYork, NY, USA, 1990.

[8] D. W. Orr, Ecological Literacy: Education and the Transition to a Postmodern World, State University of New York Press, Albany, NY, USA, 1992.

[9] L. Pittaway and J. Cope, "Entrepreneurship education," International Small Business Journal: Researching Entrepreneurship, vol. 25, no. 5, pp. 479-510, 2007.

[10] K. Cheng, Visibility of the MIT Entrepreneurship Ecosystem: MIT Undergraduate Awareness of On-Campus Entrepreneurship Resources, Massachusetts Institute of Technology, Cambridge, MA, USA, 2012.

[11] T. K. Mc Keon, "A college's role in developing and supporting an entrepreneurship ecosystem," Journal of Higher Education Outreach and Engagement, vol. 17, no. 3, pp. 85-90, 2013.

[12] L. Carvalho, T. Costa, and P. Dominguinhos, "Creating an entrepreneurship ecosystem in higher education," in New Achievements in Technology, Education and Development, S. Soomro, Ed., pp. 1-19, In Tech Open, New York, NY, USA, 2010.

[13] S. D. Dodd and B. C. Hynes, "The impact of regional entrepreneurial contexts upon enterprise education," Entrepreneurship \& Regional Development, vol. 24, no. 9, pp. 741-766, 2012.

[14] C. G. Brush, "Exploring the concept of an entrepreneurship education ecosystem," in Advances in the Study of Entrepreneurship, Innovation and Economic Growth, S. Hoskinson and D. F. Kuratko, Eds., vol. 24, pp. 25-39, Emerald Publishing Ltd, Innovative Pathways for University Entrepreneurship in the 21st Century, Bingley, UK, 2014.

[15] R. Caiazza, T. Volpe, Innovation and its diffusion: process, actors and actions," Technology Analysis \& Strategic Management, vol. 29, no. 2, pp. 181-189, 2016.

[16] C. Brown, Entrepreneurial education teaching guide, The Center for Entrepreneurial Leadership Clearinghouse on Entrepreneurship Education, Los Angeles, CA, USA, 2000, p. 8, ERIC Number: ED452430, http://www.celcee.edu/ products/digest/Dig00-7.html.
[17] G. Solomon, S. Duffy, and A. Tarabishy, "The state of entrepreneurship education in the United States: a nationwide survey and analysis," International Journal of Entrepreneurship Education, vol. 1, pp. 1-22, 2002.

[18] P. Robinson and M. Haynes, "Entrepreneurship Education in America's Major Universitys," Entrepreneurship Theory \& Practice, vol. 15, 1991.

[19] A. Lundström and L. Stevenson, Entrepreneurship policy for the future, vol. 1, p. 45, Swedish Foundation for Small BusinessResearch, Keystones of entrepreneurship knowledge, Örebro, Sweden, 2005.

[20] F. Wilson, J. Kickul, and D. Marlino, "Gender, entrepreneurial self-efficacy, and entrepreneurial career Intentions: implications for entrepreneurship education," Entrepreneurship: Theory and Practice, vol. 31, no. 3, pp. 387-406, 2007.

[21] K. C. Robinson, "An examination of the influence of industry structure on eight measures of new venture performance for high potential in dependent new ventures," Journal of Business Venturing, vol. 14, no. 2, pp. 165-187, 1998.

[22] A. Abdel-Maksoud, D. Dugdale, and R. Luther, "Non-financial performance measurement in manufacturing companies," The British Accounting Review, vol. 37, no. 3, pp. 261-297, 2005.

[23] E. W. Anderson and M. W. Sullivan, "The antecedents and consequences of customer satisfaction for firms," Marketing Science, vol. 12, no. 2, pp. 125-143, 1993.

[24] J. T. Delaney and M. A. Huselid, "The impact of human resource management practices on performance in for-profit and non-profit organizations," Academy of Management Journal, vol. 39, pp. 949-969, 2006.

[25] H. Li, K. A. Gima, and Y. Zhang, "How does new venture strategy matter in the environment-performance relationship?” The Journal of High Technology Management Research, vol. 2, no. 12, pp. 183-204, 2001.

[26] J. G. Covin and D. P. Slevin, "Conceptual model of entrepreneurship as firm behavior," Social Science Electronic Publishing, vol. 16, no. 1, pp. 5-28, 1991.

[27] B. Antoncic and R. D. Hisrich, "Intrapreneurship," Journal of Business Venturing, vol. 16, no. 5, pp. 495-527, 2001.

[28] J. J. Chrisman, A. Bauerschmidt, and C. W. Hofer, "The determinants of new venture performance: an extended model," Entrepreneurship: Theory and Practice, vol. 23, no. 1, pp. 5-29, 1998.

[29] L. Cassia, A. Colombelli, and S. Paleari, "Firms' growth: does the innovation system matter?" Structural Change and Economic Dynamics, vol. 20, no. 3, pp. 211-220, 2009.

[30] H.-C. Lee and C.-T. Chang, "Comparative analysis of MCDM methods for ranking renewable energy sources in Taiwan," Renewable and Sustainable Energy Reviews, vol. 92, pp. 883-896, 2018.

[31] Z.-h. Zou, Y. Yun, and J.-n. Sun, "Entropy method for determination of weight of evaluating indicators in fuzzy synthetic evaluation for water quality assessment," Journal of Environmental Sciences, vol. 18, no. 5, pp. 1020-1023, 2006.

[32] J. Ye, "Fuzzy decision-making method based on the weighted correlation coefficient under intuitionistic fuzzy environment," European Journal of Operational Research, vol. 205, no. 1, pp. 202-204, 2010.

[33] F. H. Lotfi and R. Fallahnejad, "Imprecise Shannon's entropy and multi attribute decision making," Entropy, vol. 12, no. 1, pp. 53-62, 2010.

[34] S. Y. Wang, W. M. Chen, and Y. Liu, "Collaborative product portfolio design based on the approach of multi choice goal 
programming," Mathematical Problems in Engineering, vol. 2021, Article ID 6678533, 16 pages, 2021.

[35] S.-Y. Wang, W.-M. Chen, and X.-L. Wu, "Competition analysis on industry populations based on a three-dimensional lotka-volterra model," Discrete Dynamics in Nature and Society, vol. 2021, Article ID 9935127, 15 pages, 2021.

[36] S.-Y. Wang, W.-M. Chen, R. Wang, and X.-L. Wu, "Multiobjective evaluation of Co-evolution among innovation populations based on lotka-volterra equilibrium," Discrete Dynamics in Nature and Society, vol. 2021, Article ID 5569108, 14 pages, 2021. 